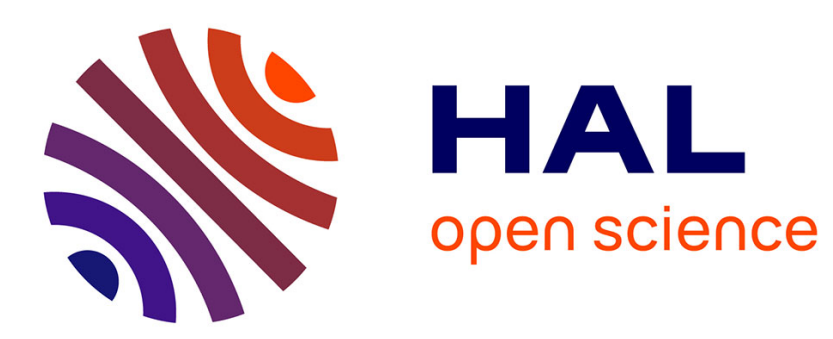

\title{
Laser-assisted chemical vapour deposition of TiSi2: aspects of deposition and etching
}

\author{
H. Westberg, M. Boman, J.-O. Carlsson
}

\section{To cite this version:}

H. Westberg, M. Boman, J.-O. Carlsson. Laser-assisted chemical vapour deposition of TiSi2: aspects of deposition and etching. Journal de Physique IV Proceedings, 1993, 03 (C3), pp.C3-225-C3-232. 10.1051/jp4:1993330 . jpa-00251387

\section{HAL Id: jpa-00251387 https://hal.science/jpa-00251387}

Submitted on 1 Jan 1993

HAL is a multi-disciplinary open access archive for the deposit and dissemination of scientific research documents, whether they are published or not. The documents may come from teaching and research institutions in France or abroad, or from public or private research centers.
L'archive ouverte pluridisciplinaire HAL, est destinée au dépôt et à la diffusion de documents scientifiques de niveau recherche, publiés ou non, émanant des établissements d'enseignement et de recherche français ou étrangers, des laboratoires publics ou privés. 


\title{
Laser-assisted chemical vapour deposition of $\mathrm{TiSi}_{2}$ : aspects of deposition and etching
}

\author{
H. WESTBERG, M. BOMAN and J.-O. CARLSSON \\ Thin Film and Surface Chemistry Group, Institute of Chemistry, Uppsala University, Box 531, \\ 75121 Uppsala, Sweden
}

\begin{abstract}
Lines of $\mathrm{TiSi}_{2}$ were written on $\mathrm{Si}(100)$ substrates by using a focused $\mathrm{Ar}^{+}$-laser. The reaction gas mixture consisted of $\mathrm{TiCl}_{4}$ and $\mathrm{H}_{2}$ and the substrate was used as the silicon source. The laser deposited $\mathrm{TiSi}_{2}$ lines were examined as a function of the deposition parameters. Especially the initial reactions have been studied by varying the the writing speed in a wide range.

The C-54 phase of $\mathrm{TiSi}_{2}$ was observed in all experiments. The geometrical shape and the surface profile of the deposited $\mathrm{TiSi}_{2}$ were complicated functions of the process parameters and the growth process itself. Substrate reactions increased the substrate etching initially. After a sufficiently thick layer of $\mathrm{TiSi}_{2}$ had been grown, thus protecting the substrate from the reaction gas mixture, the etch process stopped. By minimizing the initial substrate reactions, flat lines with respect to the substrate surface could be grown.
\end{abstract}

\section{INTRODUCTION}

$\mathrm{TiSi}_{2}$ is of interest as a gate electrode and an interconnect material in VLSI circuits because of its low resistivity and good compatibility with standard IC processing techniques. For these applications it is important that the substrate surface remains relatively flatduring thedeposition process. The molar volume difference between $\mathrm{Si}$ and $\mathrm{TiSi}_{2}$ is only $7 \%$. Thus by using the substrate as the silicon source and an external titanium sourece (e.g. from the vapor) relatively flat $\mathrm{TiSi}_{2}$ lines can be grown [1]. In this paper we have used thermal laser assisted chemical vapor deposition (LCVD) to grow $\mathrm{TiSi}_{2}$ lines on a silicon substrate.

LCVD using a focused laser beam perpendicular to the substrate surface is a very complex process. This is partly because of a gaussian intensity distribution of the laser beam which generates a temperature gradient across the spot on the substrate or on the deposited material. The temperature gradient may alter the chemistry over the laser processed spot resulting in differences in the phase composition and/or chemical composition.

Generally the deposition time in LCVD is very short. This means that the initial reactions will dominate the deposition process. Initially the substrate is exposed to the reaction gas mixture. If the substrate is chemically reactive towards the gas phase, substrate etching will occur with the formation of gaseous substrate compounds. Later on, when the deposited material has protected the substrate surface from the reaction gas mixture, the etch reaction will be slower. Occurrence of such initial etch reactions may influence

- the adhesion. If an etching process occurs it might result in a corrosion attack on the substrate, yielding poor adhesion of the laser deposited material.

- chemical and phase composition of the laser deposited material. Gaseous substrate compounds may after transport in the vapour, be redeposited at a substrate location having a lower acti vity with respect to the transported substrate element than the location where the reactive evaporation took place. 
- the deposition rate and grain size of the laser deposited material. The etch reaction often increases the driving force of the CVD process and hence the deposition rate. This may result in a more finegrained deposit near the substrate/coating interface. Subsequently in the process, when the substrate is not exposed to the vapour, a larger-grained deposit may be expected.

Depending on the scanning velocity the relative influence of the initial reactions, e.g. substrate etching, on the process will be different. For a high scanning velocity, i.e., a short deposition time, the etch reaction may dominate the deposition process entirely.

$\mathrm{TiSi}_{2}$-lines were deposited from a reaction between the substrate silicon and a gas mixture consisting of $\mathrm{TiCl}_{4}$ and $\mathrm{H}_{2}$. This deposition process can be described approximately by the overall reactions,

$$
\begin{gathered}
\mathrm{TiCl}_{4}(\mathrm{~g})+6 \mathrm{Si}(\mathrm{s})+6 \mathrm{H}_{2}(\mathrm{~g}) \rightarrow \mathrm{TiSi}_{2}(\mathrm{~s})+4 \mathrm{SiH}_{3} \mathrm{Cl}(\mathrm{g}) \\
\mathrm{TiCl}_{4}(\mathrm{~g})+2 \mathrm{Si}(\mathrm{s})+2 \mathrm{H}_{2}(\mathrm{~g}) \rightarrow \mathrm{TiSi}_{2}(\mathrm{~s})+4 \mathrm{HCl}(\mathrm{g})
\end{gathered}
$$

In reaction (1) the $\mathrm{TiCl}_{4}$ is reduced by the silicon substrate and in the second reaction $\mathrm{TiCl}_{4}$ is reduced by hydrogen. This means that either $\mathrm{SiH}_{3} \mathrm{Cl}$ or $\mathrm{HCl}$ are formed in addition to $\mathrm{TiSi}_{2}$. However, there are several other possible reaction pathways where different gaseous chlorosilanes, $\mathrm{SiH}_{x} \mathrm{Cl}_{4 \cdot \mathrm{x}}(0 \leq \mathrm{X} \leq$ 4), are formed. The reaction pathway depends mainly on the $\mathrm{H}_{2} / \mathrm{TiCl}_{4}$ molar ratio and the deposition temperature. Since the silicon substrate is reactive towards the gas phase etching of the substrate will take place.

A considerable substrate etching under the laser deposited lines was earlier observed in LCVD of $\mathrm{TiSi}_{2}$ [1]. Frequently a larger etching was found along the edges than in the centre of the line. This means that the surface profiles perpendicular to the laser-written lines were bimodal in shape.

In the present investigation the deposition conditions have been varied in wide ranges to study the effect on the surface profile, the growth kinetics and the morphologies. The importance of the deposition time was especially examined. $\mathrm{TiSi}_{2}$ has previously been deposited by thermally activated CVD, plasma-activated CVD and also laser-induced CVD[1-7].

\section{EXPERIMENTAL}

The laser system is schematically shown in Figure 1. Details of the system have been presented elsewhere [8] and only a brief description is given here.

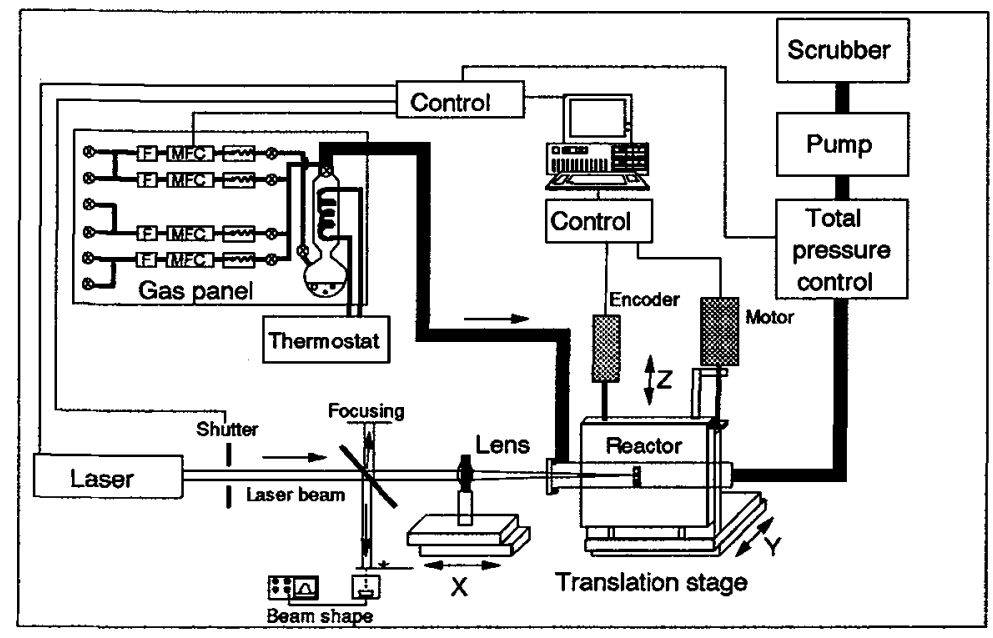

Fig. 1. Sketch of the LCVD system

A cw Argon ion laser, Innova $100 \mathrm{UVE}+$, was operated at a wavelength of $514.5 \mathrm{~nm}$. The gaussian beam shape was used throughout the experiments. The laser beam was at perpendicular incidence and focused through a quartz window onto the substrate. The spot diameter was measured to be, $2 \omega_{0}$ $=21 \mu \mathrm{m},\left(1 / \mathrm{e}^{2}\right.$ decrease in intensity) according to the scanning knife edge method [9]. The laser speckle method was used to get the substrate in the focal plane. For the direct writing, the reaction chamber 
and the focusing lens were placed on computer controlled high resolution $x-y-z$ stages with a mechanical resolution of $4 \mathrm{~nm}$, an accuracy of $0.5 \mu \mathrm{m}$ and a speed range of $4 \mathrm{~nm} / \mathrm{s}-4 \mathrm{~mm} / \mathrm{s}$. The laser power was continuously measured during the deposition experiments.

The experiments were performed in an open cold wall CVD reactor. A gas handling system and an evaporator for $\mathrm{TiCl}_{4}$ were used to provide the reactor with the reaction gas mixture. For control of the total pressure an automatic pressure controller was employed.

\subsection{Deposition conditions}

Silicon (100) (P doped, resistivity $10 \Omega \mathrm{cm}$ ) wafers were used as substrates. The gaseous reactants, $\mathrm{H}_{2}$ and $\mathrm{TiCl}_{4}$, had a purity of $99.9997 \%$ and $99,995 \%$, respectively. For the $\mathrm{TiSi}_{2}$ growth the substrate was used as the silicon source.

Prior to the deposition experiments, the substrates were cleaned by first oxidizing in an $\mathrm{H}_{2} \mathrm{O}_{2} / \mathrm{H}_{2} \mathrm{SO}_{4}$ mixture for 10 minutes at $95^{\circ} \mathrm{C}$ and then etching in $\mathrm{HF}(10 \%)$ for 10 seconds. This cleaning procedure yields a hydrogen terminated surface. The substrate will remain hydrogenated even after transport in the atmosphere and only small amounts of oxygen on the surface can be seen. Hydrogen is desorbed in the LCVD process when the temperature has increased to about $400^{\circ}[10]$, leaving a clean silicon surface exposed to the reaction gas mixture. After the deposition, the subchlorides, which condensed just outside the heated region, were removed by a dip in $2 \mathrm{M}$ hydrochloric acid for a few seconds. The laser power density and the scanning velocity were varied in the range $6.8-8.5 \cdot 10^{5} \mathrm{~W} / \mathrm{cm}^{2}$ and 1.0 $600.0 \mu \mathrm{m} / \mathrm{s}$, respectively. The $\mathrm{H}_{2} / \mathrm{TiCl}_{4}$ molar ratio was varied in the range $900 / 1$ to $900 / 9$.

\subsection{Characterization}

Phase analysis and texture investigation were performed by X-ray diffractometry (XRD) using a powder diffractometer with $\mathrm{CuK}_{\alpha}$ radiation. The chemical composition was determined by Auger Electron Spectroscopy (AES). The morphology and the microstructure were investigated by scanning electron microscopy (SEM).

To obtain the film thickness, cross-sections of the deposited lines were measured from SEM micrographs. For the preparation of the cross-sections, glueing of specimen to another silicon wafer was used. This procedure reduces the degradation of the surfaces, including the lines, during the polishing. By sequential polishing, several cross-sections could be measured from each line. The substrate etching and profile of the line perpendicular to the scanning direction were examined by a profilometer (depth resolution $50 \AA$ ). The substrate etching was defined as the distance between the substrate surface and the $\mathrm{TiSi}_{2}$ deposit in the centre of the laser deposited line.

\subsection{Temperature determination}

Temperature measurements are very difficult to perform in focused beam LCVD since the heated area is small and since the temperature varies across the laser spot on the substrate surface. However, the temperature can be calculated if the thermal conductivity and the reflectivity of the substrate and the deposit are known as a fuction of temperature. For a presentation of the temperature calculation technique and the thermal constants used in $\mathrm{LCVD}$ of TiSi ${ }_{2}$, see ref. [1]. Throughout this paper, both the laser power density and the highest laser induced temperature refer to the centre of the laser spot. This temperature was calculated for silicon [1], i.e., the laser induced temperature prior to any deposition of $\mathrm{TiSi}_{2}$.

\section{RESULTS}

\subsection{Surface profiles}

Figure 2 shows the surface profiles (obtained from profilometer measurements) as a function of inverse scanning velocity. Since the inverse scanning velocity is proportional to the deposition time, the figures show the thickness of the $\mathrm{TiSi}_{2}$ lines as a function of time and represent different stages of growth. The deposited $\mathrm{TiSi}_{2}$ region, also showed in Fig. 2, is dashed and has been drawn from SEM cross-sections.

Etching of the silicon substrate could only be avoided for $\mathrm{TiSi}_{2}$ lines deposited at scanning velocities exceeding $600 \mu \mathrm{m} / \mathrm{s}(1.7 \mathrm{~ms} / \mu \mathrm{m})$. However, no deposition or only a few scatterd nuclei of $\mathrm{TiSi}_{2}$ were observed at such short deposition times. The small increase in thickness shown in Figure 2a represents the surface profile of the line deposited at $300 \mu \mathrm{m} / \mathrm{s}$. The deposit is slightly elevated in the centre of the line. This indicates a low etch rate of the substrate. 

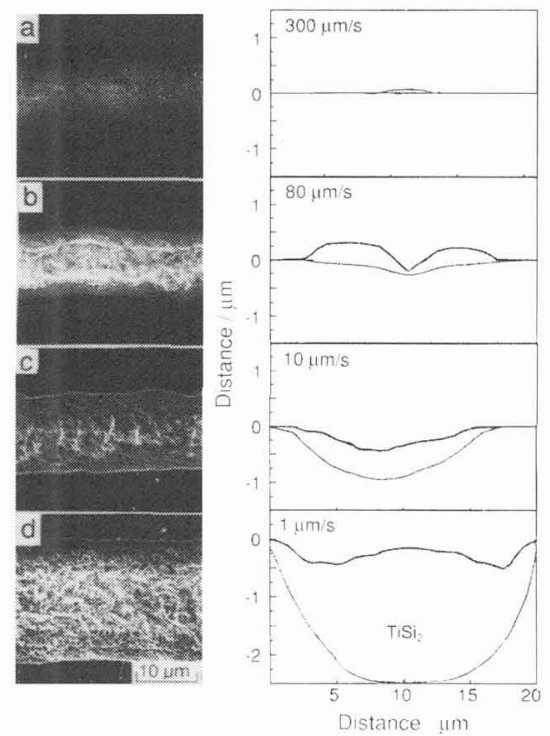

Fig. 2. Morphology and surface profiles of laser deposited TiSi $i_{2}$ lines as a function of scanning velocity. Laser power density: $7.74 \cdot 10^{5} \mathrm{~W} / \mathrm{cm}^{2}(1460 \mathrm{~K})$. Molar ratio $\mathrm{H}_{2} / \mathrm{TiCl}_{4}: 900 / 1$.
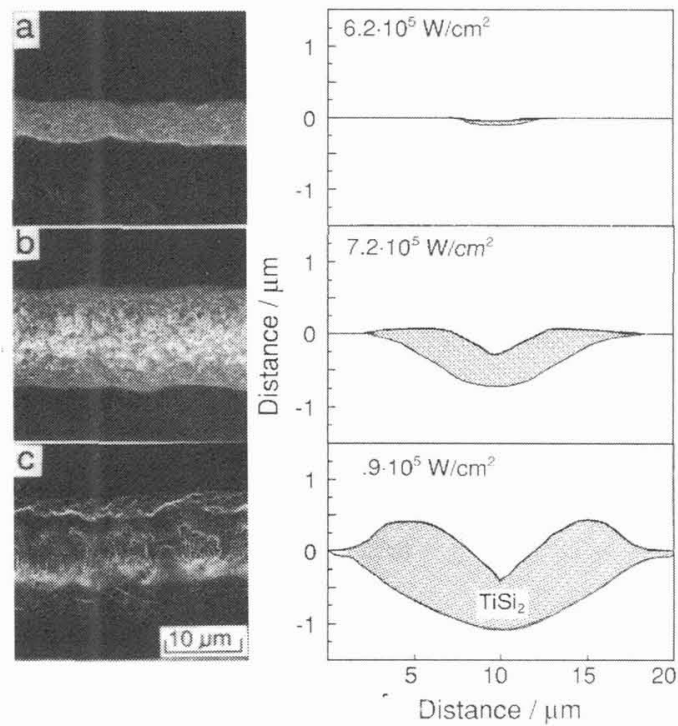

Fig. 3. Morphology and surface profiles of laser deposited $\mathrm{TiSi}_{2}$ lines as a function of laser power density. Scanning velocity: $10 \mu \mathrm{m} / \mathrm{s}$. Molar ratio $\mathrm{H}_{2} / \mathrm{TiCl}_{4}: 900 / 1$. 
Fig $2 \mathrm{~b}$ shows the surface profile of a line deposited at a lower scanning velocity $(80 \mu \mathrm{m} / \mathrm{s})$. This surface profile shows that the substrate has been slightly etched in the centre and that the deposit is elevated above the surface level along the edges. This type of surface profile is frequently observed in laser melted materials structures.

At a somewhat longer deposition time $(100 \mathrm{~ms} / \mu \mathrm{m})$, at a scanning velocity of $10 \mu \mathrm{m} / \mathrm{s}$, the elevation along the edges of the line has been suppressed and the surface profile is concave with a maximum etch depth of $0.4 \mu \mathrm{m}$, see Fig $2 \mathrm{c}$. At the longest deposition time examined $(1.0 \mathrm{~s} / \mu \mathrm{m})$, the largest etch depth (about $0.5 \mu \mathrm{m}$ ) was found along the edges of the line. In the centre of the line the etch depth was considerably smaller and a bimodal surface profile was obtained.

Fig 3 a-c shows the surface profiles of laser deposited $\mathrm{TiSi}_{2}$ as a function of the laser power density. Increasing the laser power density from $6.2 \cdot 10^{5} \mathrm{~W} / \mathrm{cm}^{2}(1180 \mathrm{~K})$ to $7.9 \cdot 10^{5} \mathrm{~W} / \mathrm{cm}^{2}(1490 \mathrm{~K})$ means that the etch depth in the centre of the laser processed area will increase from $0.04 \mu \mathrm{m}$ to about $0.4 \mu \mathrm{m}$. On both sides and at distances 5 and $15 \mu \mathrm{m}$ of the etch groove the etch rate is lower and the deposit is slightly above the surface, see Fig $3 \mathrm{~b}$ and $3 \mathrm{c}$. The surface profile in Fig. 3c indicates surface melting of the deposited $\mathrm{TiSi}_{2}$.

\subsection{Morphology and microstructure}

Figure 2 a-d shows the morphology of the laser deposited $\mathrm{TiSi}_{2}$ lines as a function of scanning velocity. Theinitial stage of growth is represented by the fastest scanning velocity used, $600.0 \mu \mathrm{m} / \mathrm{s}(1.67 \mathrm{~ms} / \mu \mathrm{m})$, not shown in Fig. 2. The silicon substrate was affected in an irregular manner and a random nucleation of $\mathrm{TiSi}_{2}$ was observed. At a somewhat longer deposition time, at a scanning velocity of $300.0 \mu \mathrm{m} / \mathrm{s}(3.3$ $\mathrm{ms} / \mu \mathrm{m})$, periodic surface structures started to appear in the centre of the laser heated region (Fig. 2 a). The surface structure, so called ripples, had a spacing of approximately $0.4 \mu \mathrm{m}$. This is slightly shorter than the wavelength used $(0.514 \mu \mathrm{m})$. The ripples run normal to the electric field vector of the incident polarized laser beam. A rippled morphology of the deposited $\mathrm{TiSi}_{2}$ was observed for all scanning velocities except at $1 \mu \mathrm{m} / \mathrm{s}$ where a relative thick film of $2.5 \mu \mathrm{m}$ had developed. At this scanning velocity the deposit was rough and porous. Whiskers were also frequently observed.

The laser power density, i.e. the temperature, strongly influenced the morphology of the laser deposited $\mathrm{TiSi}_{2}$ lines, see Fig. 3. The morphology of the line deposited at the lowest laser power density, $6.2 \cdot 10^{5}$ $\mathrm{W} / \mathrm{cm}^{2}(1180 \mathrm{~K})$, was fine-grained, smooth and free from pores and cracks (Fig. 3a). The line was thin, $5.4 \mu \mathrm{m}$ wide, but well defined along the edges. Cracks and pores appeared in the centre of the deposit when the laser power density was increased. This is seen in figure $3 \mathrm{~b}$ which shows a line deposited at $7.2 \cdot 10^{5} \mathrm{~W} / \mathrm{cm}^{2}(1380 \mathrm{~K})$. At this laser power density a periodic surface structure was observed. Increasing the laser power density to $7.9 \cdot 10^{5} \mathrm{~W} / \mathrm{cm}^{2}(1490 \mathrm{~K})$, resulted in a much more developed periodic surface structure, see Fig. 3c.

The best quality $\mathrm{TiSi}_{2}$ with respect to smoothness and porosity was obtained at scanning velocities of at least $20 \mu \mathrm{m} / \mathrm{s}$ and at laser power densities ranging from about $6.2 \cdot 10^{5}(1180 \mathrm{~K})$ to $7.2 \cdot 10^{5} \mathrm{~W} / \mathrm{cm}^{2}$ $(1380 \mathrm{~K})$. In this range, the scanning velocity is high enough to avoid whisker-like growth and the laser power density is sufficiently low to avoid formation of cracks and a rippled surface structure. A higher linear gas flow velocity further improved the quality of the deposit. A more fine-grained and smoother morphology was obtained and whisker-like growth was suppressed. When the total pressure was increased ten times to 75 torr, the deposition rate increased several times. The lines were nolonger embedded in the silicon substrate but elevated from it. The morphology was in most cases very porous and the grain size was small $(0.1-0.2 \mu \mathrm{m})$.

\subsection{Chemical and phase composition}

$\mathrm{X}$-ray diffraction showed that the laser deposited material contained the orthorhombic C-54 modification of $\mathrm{TiSi}_{2}$ having a (001) texture.

The AES analysis showed that the composition of the laser deposited lines was close to $\mathrm{TiSi}_{2}$, except for lines deposited for long times $(1 \mu \mathrm{m} /$ and $2 \mu \mathrm{m} / \mathrm{s})$ where an excess of titanium was observed with respect to $\mathrm{TiSi}_{2}$. All the $\mathrm{TiSi}_{2}$ lines contained a large amount of oxygen even after sputtering prior to the analysis. $\mathrm{TiSi}_{2}$ is known to oxidize very fast in the air and a mixed titanium-silicon oxide is formed. No chlorine was observed in the spectra.

The granular structure found initially (at $1.7 \mathrm{~ms} / \mu \mathrm{m}$ ) on the silicon surface, i.e., at the highest scanning velocity, consisted mainly of titanium oxide $\left(\mathrm{TiO}_{\mathrm{x}}\right)$. The rippled surface structure contained a lower content of titanium and also a higher content of silicon than the granular structure. This indicated that the silicide formation had started and that the rippled structure appeared in connection with this. The titanium and also the silicon content was found to vary across the line. In the centre of the line 
and of the surface structure, the titanium content was lower and the amount of silicon was higher than along the edges. This tendency is enhanced for lines deposited at higher laser power densities, when the rippled structure is more developed.

\subsection{Kinetics}

In this section, the dependence of film thickness and etch depth is presented as a function of process parameters. Both the film thickness and the etch depth, which are shown in the following figures, were measured in the centre of the lines.

Neither the film thickness nor the etch depth were influenced by the linear gas flow velocities in the range $22-176 \mathrm{~cm} / \mathrm{s}$. This indicates that the process is surface reaction controlled.

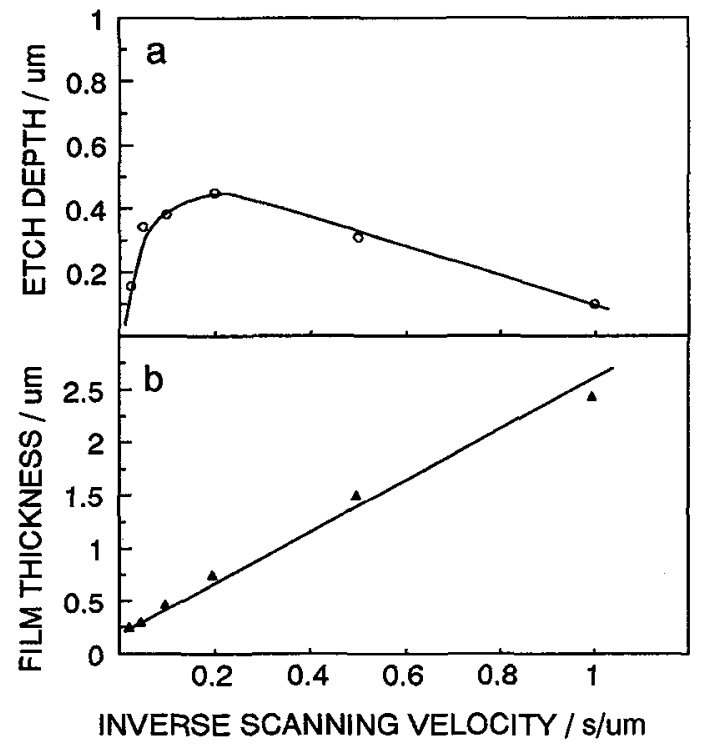

Fig. 4. Etch depth (a) and thickness of $\mathrm{TiSi}_{2}$ (b) as a function of the inverse scanning velocity. Laser power density: $7.6 \cdot 10^{5} \mathrm{~W} / \mathrm{cm}^{2}(1450 \mathrm{~K})$. Molar ratio $\mathrm{H}_{2} / \mathrm{TiCl}_{4}: 900 / 1$

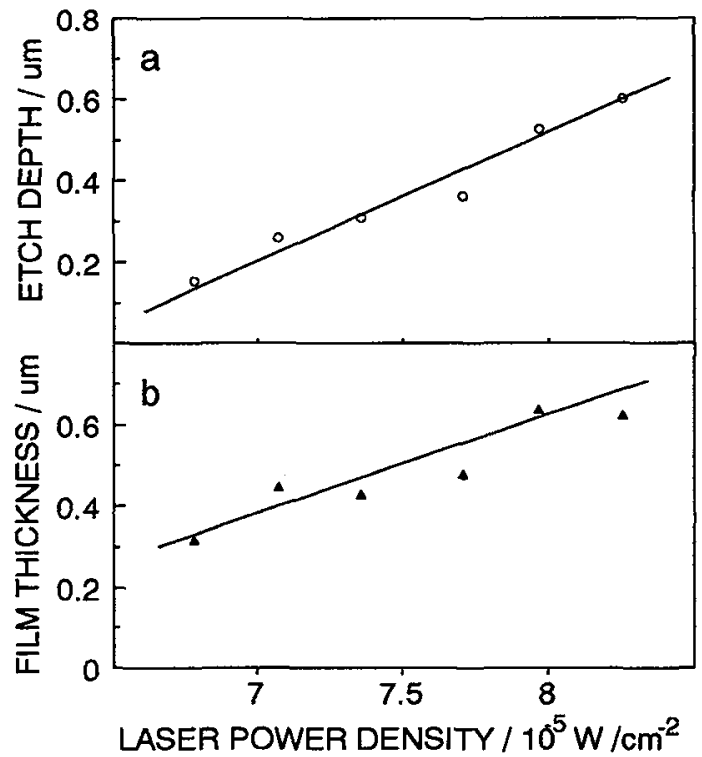

Fig. 5. Etch depth (a) and thickness of $\mathrm{TiSi}_{2}$ (b) as a function of the laser power density. Scanning velocity: $10 \mu \mathrm{m} / \mathrm{s}$. Molar ratio $\mathrm{H}_{2} / \mathrm{TiCl}_{4:}: 900 / 1$.

Figure 4 shows the film thickness and etched depth as a function of inverse scanning velocity. Bimodal surface profiles were obtained for the lines deposited at 1.0 and $2.0 \mu \mathrm{m} / \mathrm{s}$. The film thickness increased linearly, from 0.26 to $2.5 \mu \mathrm{m}$, with increasing deposition time. Initially, the etch depth increased very fast with increasing inverse scanning velocity and at about $0.2 \mu \mathrm{m} / \mathrm{s}$ a maximum in etch depth, 0.45 $\mu \mathrm{m}$, was obtained. For higher inverse scanning velocities the etch depth decreased and was at $1 \mathrm{~s} / \mu \mathrm{m}$ $0.1 \mu \mathrm{m}$. Both the film thickness and the etch depth were found to increase linearly with increasing laser power density, see Fig. 5. The film thickness increased from 0.34 to $0.65 \mu \mathrm{m}$ and the etched depth from 0.16 to $0.60 \mu \mathrm{m}$ between $6.8 \cdot 10^{5}(1300 \mathrm{~K})$ and $\left.8.3 \cdot 10^{6} \mathrm{~W} / \mathrm{cm}^{2} 1520 \mathrm{~K}\right)$.

In order to gain some insight in the type of process controll, data from Fig. 5 was plotted in an Arrhenius diagram and a rough estimate of the apparent activation energy AAE could be made, see Fig 6 . The laser power density was converted to temperature by using the calculated laser induced temperature on a silicon substrate, i.e., representing initial conditions prior to any deposition of $\mathrm{TiSi}_{2}$. The (AAE) for both deposition and etching was found to be low, about $45 \mathrm{~kJ} / \mathrm{mol}$ and $90 \mathrm{~kJ} / \mathrm{mol}$, respectively.

Fig. 7 shows the influence of the $\mathrm{TiCl}_{4}$-concentration on the deposition and etch rate. The film thickness increases linearly with the $\mathrm{TiCl}_{4}$-concentration up to $0.6 \%$ irrespective of the scanning velocity. The film thickness decreased between 0.6 and $1 \% \mathrm{TiCl}_{4}$ in the gas phase and for 2 and $5 \mu \mathrm{m} / \mathrm{s}$ in scanning velocity. Also the etched depth increased linearly with increasing $\mathrm{TiCl}_{4}$ concentration for lines deposited at scanning velocities of 5.0 and $10.0 \mu \mathrm{m} / \mathrm{s}$. Another dependence was obtained for the lowest scanning velocity, $2.0 \mu \mathrm{m} / \mathrm{s}$. After a slow increase in the etch depth up to about $0.6 \% \mathrm{TiCl}_{4}$ the increaseaccelerates towards the highest $\mathrm{TiCl}_{4}$-concentration. The high increase in etch rate at this high $\mathrm{TiCl}_{4}$-concentration was followed by a decrease in the deposition rate. 


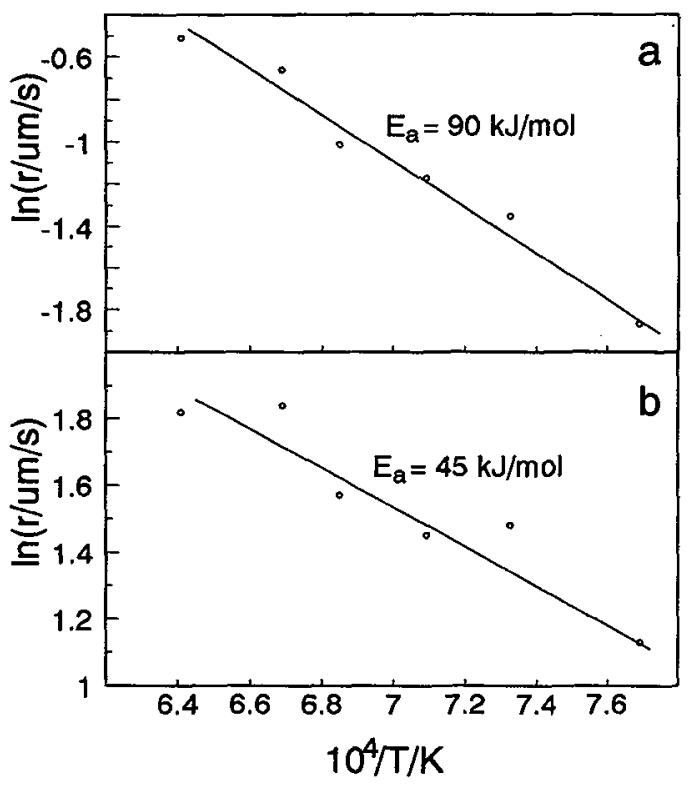

Fig. 6. Etch depth (a) and film thickness (b) represented in Arrhenius' curves. Scanning velocity: $10 \mu \mathrm{m} / \mathrm{s}$. Molar ratio $\mathrm{H}_{2} / \mathrm{TiCl}_{4}: 900 / 1$.

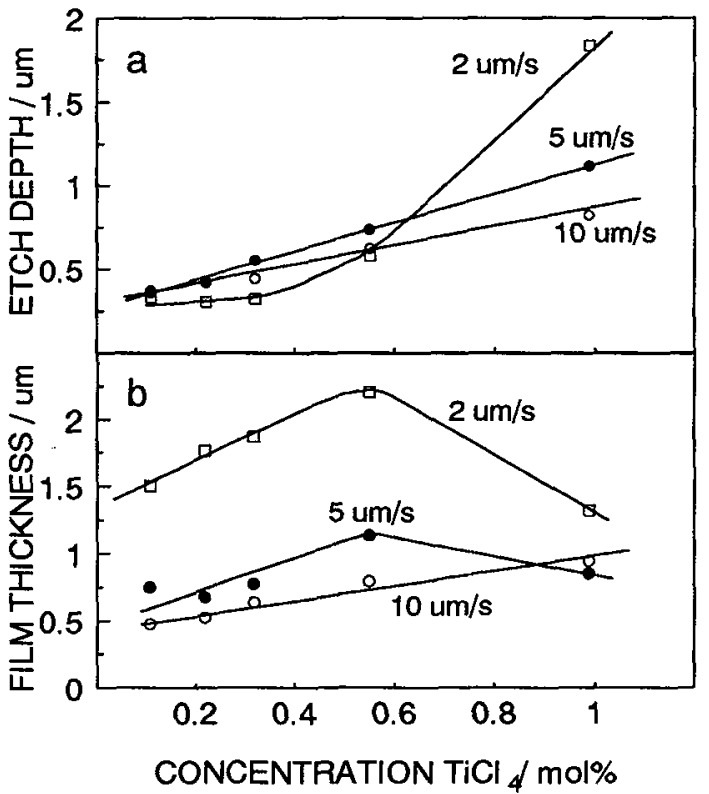

Fig. 7. Etch depth (a) and thickness of the TiSi deposit (b) as a function of molar ratio $\mathrm{H}_{2} / \mathrm{TiCl}_{4}$. Scanning velocity: $10 \mu \mathrm{m} / \mathrm{s}$. Laser power density: $7.6 \cdot 10^{5} \mathrm{~W} / \mathrm{cm}^{2}(1450 \mathrm{~K})$.

\section{DISCUSSION}

The threshold temperature for the silicide formation between $\mathrm{Si}$ and a thin layer of $\mathrm{Ti}$ is reported to be about $800 \mathrm{~K}$ [11]. However, initial interfacial reactions which involves titanium-silicon intermixing has been observed at lower temperatures, about $570 \mathrm{~K}$ [11]. The growth of the silicide from $\mathrm{Si}$ and Ti shows a parabolic behaviour which indicates that the process is limited by a transport through the silicide layer. The activation energy of this diffusion reaction is reported to be $1.8 \mathrm{eV}(170 \mathrm{~kJ} / \mathrm{mol})$ [12].

An LCVD process where $\mathrm{TiSi}_{2}$ is formed from $\mathrm{TiCl}_{4} / \mathrm{H}_{2} / \mathrm{Si}$ is more complicated and can be controlled by mass transport in the vapour, surface kinetics and/or solid state diffusion. If the deposition time is short the process can also be controlled by the nucleation. Since the chemical processes responsible for film growth varies with the film thickness, different types of process controll may be present at different stages of growth. Initially the silicon substrate is exposed to the reaction gas mixture. Since $\mathrm{Si}$ is a better reducing agent than $\mathrm{H}_{2}$ towards $\mathrm{TiCl}_{4}$ the driving force of the process and hence the reaction rate may be high initially, after nucleation. This may result in a mass transport controlled process. Later on when the substrate is separated from the vapour by the growing $\mathrm{TiSi}_{2}$, the growth rate decreases and the process becomes surface kinetically controlled. When a thick layer of $\mathrm{TiSi}_{2} \mathrm{has}$ been grown, the diffusion resistance of $\mathrm{Si}$ through $\mathrm{TiSi}_{2}$ becomes higher and the process will be controlled by the solid state diffusion of $\mathrm{Si}$.

At the shortest deposition times (highest scaning velocities 600 and $300 \mu \mathrm{m} / \mathrm{s}$ ) LCVD of $\mathrm{TiSi}_{2}$ from $\mathrm{TiCl}_{4} / \mathrm{H}_{2} / \mathrm{Si}$ was probably limited by nucleation. For longer deposition times a low activation energy $(45 \mathrm{~kJ} / \mathrm{mol})$ indicated a mass transport controlled process. However, a mass transport controlled process is sensitive to variations in the linear gas flow velocity. This was not verified by the experiments. On the contrary the film thickness was independent on the linear gas flow velocity. The linear dependence of the film thickness as a function of deposition time excludes a solid state diffusion controlled process which has a parabolic dependence. The most probable type of control is therefore surface kinetics having a low AAE.

The geometrical shape and the surface profile of the deposited $\mathrm{TiSi}_{2}$ is a complicated function of the process parameters and the growth process itself. The rapid increase in etch rate with increasing deposition time (up to $0.2 \mathrm{~s} / \mu \mathrm{m}$ ) as shown in Fig. 4, can be explained by the fact that the substrate is exposed to the reaction gas mixture and reaction (1) dominates. When the substrate becomes completely covered by $\mathrm{TiSi}_{2}$ the etch process stops at deposition times longer than $0.2 \mathrm{~s} / \mu \mathrm{m}$. This reflects the fact that reaction (2) becomes more important. The surface profile as a function of deposition time then 
strongly depends on the development and growth of the $\mathrm{TiSi}_{2}$-layer, separating the substrate from the reaction gas mixture. At 80 and $10 \mu \mathrm{m} / \mathrm{s}(0.0125$ and $0.1 \mathrm{~ms} / \mu \mathrm{m}$, respectively) the etch depth is highest in the centre of the deposited line, see Fig. 2. For even longer deposition times the $\mathrm{TiSi}_{2}$ deposit grows thick in the centre of the line. Since the silicon substrate now is effectively separated from the reaction gas mixture, the etch rate is low and reaction (1) is dominating. A low etch rate combined with a volume increase $(7 \%)$ during growth of $\mathrm{TiSi}_{2}$ means that the etch depth in the centre of the string will be suppressed resulting in a bimodal surface profile.

The surface profile in Figures $2 \mathrm{c}, 3 \mathrm{~b}$ and $3 \mathrm{c}$ indicated surface melting of the deposited $\mathrm{TiSi}_{2}$ at laser power densities lower than expected $\left(7.7 \cdot 10^{5} \mathrm{~W} / \mathrm{cm}^{2}, \mathrm{~T}=1460 \mathrm{~K}\right)$ - the estimated laser induced temperature was lower than the melting point of both $\mathrm{Si}$ and $\mathrm{TiSi}_{2}$. This was supported by experiments performed in a hydrogen atmosphere in order to study surface melting of silicon. A minimum laser power density of $8.9 \cdot 10^{5} \mathrm{~W} / \mathrm{cm}^{2}$ was required to melt the silicon at a scanning velocity $=580 \mu \mathrm{m} / \mathrm{s}$ (calculated temperature: $1680 \mathrm{~K}$ ). In Figures $2 \mathrm{c}, 3 \mathrm{~b}$ and $3 \mathrm{c}$ a rough and rippled morph was observed. This will decrease the reflectivity due to multiple reflection on the $\mathrm{TiSi}_{2}$ surface and a higher temperature than calculated will result. The lowest possible melting temperature $(1600 \mathrm{~K})$ in the Ti-Si system is an eutecticum at 83 at\% $\mathrm{Si}$ which then must have been exceeded.

Periodic surface structures, so called ripples, were obtained at an early stage of growth at relatively high laser power densities $\left(7.7 \cdot 10^{5} \mathrm{~W} / \mathrm{cm}^{2}\right)$. There have been several attempts to explain the occurrence of the ripples [13]. Generally, it is believed that ripples arise because of an interference effect between incident and scattered light.

Ripples was also observed in the previous paper in $\mathrm{LCVD}$ of $\mathrm{TiSi}_{2}$ [1]. A minimum laser power density of $9.5 \cdot 10^{5} \mathrm{~W} / \mathrm{cm}^{2}$ and a low scanning velocity $(2 \mu \mathrm{m} / \mathrm{s})$ were then required to produce the ripples. This laser power density corresponds to a temperature which is sufficiently high to melt the $\mathrm{TiSi}_{2}$ deposit. The laser power density, $7.7 \cdot 10^{5} \mathrm{~W} / \mathrm{cm}^{2}$, which was used in this investigation corresponds to a too low calculated temperature to cause surface melting according to the discussion above.

\section{Acknowledgement}

The financial support of this project by SECO Tools AB and the Swedish Board for Technical Development is gratefully acknowledged.

\section{REFERENCES}

[1] H. Westberg, F. Ericson, J. Engquist, M. Boman and J.-O. Carlsson, Thin Solid Films, 198 (1991) 279.

[2] J. Engquist, J.-O. Carlsson and C. Myers, J. Electrochem. Soc., 139, (1992) 3197.

[3] A. Bouteville, A. Royer and J.C. Remy, J. Electrochem. Soc., 134 (1987) 2080.

[4] V. Ilderem and R. Reif, J. Electrochem. Soc. 135 (1988) 2590.

[5] R.S. Rosler and G.M. Engle, J. Vac. Sci. Technol. B, 2 (1984) 733.

[6] G.A. West, A. Gupta and K.W. Beeson, Appl. Phys. Lett., 47 (1985) 476.

[7] G.A. West, K.W. Beeson and A. Gupta, J. Vac. Sci. technol. A, 3 (1985) 2278.

[8] M. Boman, H. Westberg and Jan-Otto Carlsson, UUIC-249 (1992).

[9] Y. Suzaki and A. Tachibana, Appl. Opt., 18 (1979) 1042.

[10] U. Jansson and J.-O. Carlsson, to be published.

[11] B. Noläng, Thesis, Acta Univ. Ups. (Fac. Sci.) 691 (1983).

[11] R. Butz, G.W. Rubloff and P.S. Ho, J. Vac. Sci. Technol., A1 (1983) 771.

[12] L.S. Hung, J. Guylai, J.W. Mayer, S.S. Lan and M.-A. Nicolet, J. Appl. Phys. 54 (1983) 5076.

[13] H.M. van Driel, J.E. Sipe and J.F. Joung, J. Luminesc., 30 (1985) 446. 